\title{
The Current Situation and Development Discussion of Chinese Clothing
}

\section{Structure Design}

\author{
Xiuqing Wang ${ }^{1}$ \\ ${ }^{1}$ Jiangxi Institute of Fashion Technology, Nanchang Jiangxi, China, 330201
}

KEYWORDS: Clothing, Structure Design, Current Situation, Development Discussion

\begin{abstract}
People often say that clothes make the man, the Buddha by Gold, clothing is a manifestation of a person's external image. Studies show that with the rapid economic growth in China, the national consumption level is gradually improving, particularly reflected in the national consumption of clothing. China is the largest producer of labor, garment manufacturing and production requires a lot of labor, for the present, in China, high-end clothing design trend has become increasingly evident. PREVIEW Industrial Research Institute Monitoring Center data show that in 2010 China's consumption of clothing, high-end apparel consumption growth of 31.2\%, midrange and low growth were $19.2 \%$ and $18.4 \%$. In 2011, prices rose sharply due to the brand women $35.7 \%$, clothing sales growth fell, but sales of high-end women still reached $20 \%$ growth rate. The following describes the specific status and development of Chinese clothing design.
\end{abstract}

\section{Research on Chinese Clothing Structure Design}

China is an ancient nation, with five thousand years of history and culture, clothing is one of the representatives of Chinese culture. Ancient dressy accessories, such as belts, jade, and so on, and now the level of enhanced national strength, China's rapid economic development, people's clothing requirements are getting higher and higher. More consumers in the choice of clothing when not only requires good quality clothing, wear comfortable clothing, but also to consider the structural design of clothing, because the three-dimensional garment design modification can be a good one drawback body, the more people off good-looking, so in recent years, can clearly find Chinese clothing design becoming more and more high-end, a further move towards international standards, and gradually with international standards, integration, and create their brand of Chinese culture.

According to incomplete statistics analysis, starting in 2008, China's clothing market began to favor high-end women's clothing apparel design, once reached the top ten share, based on the structural design of high-end clothing strong incoming Chinese apparel market, a lot of brand market suffered a serious impact, also have the advantage of no moment. The main reason leading to this result is now China's garment industry is the replacement period, in the transition from high school to the low-end consumer choice selection of low consumption periods, and mature ladies industry because the company was founded, the Chinese apparel industry little contact, for the development of the industry is also poorly understood, so for the Chinese high-end women's apparel industry of costume design grasp properly, did not control, nor a good industry to seize the opportunity, it will off guard, not prepared to deal with measures, so as to cause serious impact on the market. But as long as women mature industry grasp the dynamic development of the industry, in the clothing structural design innovation to make more mature ladies industry will develop more and better, with unlimited possibilities, and has a very broad market prospects. 
Organized by the China International Garment Fair every year it is exceptionally hot, which is a major event in China's apparel industry. The annual China International Garment Fair has nearly 30 countries and regions represented, clothing exhibitors over more than 3,000 exhibitors, however, different from the past organized by the China International Garment Fair, this year, the vast majority of apparel exhibitors in previous years, the lack of respect the pride, greatly reducing the investment funds, mainly a lot of clothing exhibitors this year reflect a significant reduction in the amount of clothing orders, relative to previous years, the fair business is also showing a downward trend. According to the exhibitors China International Clothing Fair revealed that this year reflects the customer's point of view from foreign customers for products and kinds of clothing remained largely unchanged, but may be affected by the international situation, when many foreign customers in order varieties of clothing, if orders is 10 , then at least more than half of all clothing choice is the new varieties and new varieties are in the structural design of clothing on innovation, and in order to highlight the clothing structure design, in the selection of textile fabrics is also very carefully, considerations. But now textile fabrics market environment is not optimistic, starting in 2012, the price of imported textile fabric all the way by leaps and bounds, more than $20 \%$ year on year growth rate, which for the development of China's garment industry has great influence, many Chinese clothing business dilemma facing closure, survive garment enterprises is not easy. Especially downstream of the low-end clothing business clothing inventory backlog is very serious, and upstream of the high-end clothing enterprises is relatively lesser extent, but the company still faces pressure should not be underestimated. Downstream of the low-end garment enterprises are facing difficulties in order to change, try to start in terms of market development, structural adjustment clothing design companies to promote sales of wearing apparel. Development of the market, the market can get more useful information to help downstream low-end garment enterprises timely change of clothing design business, comply with the development needs of the market; timely adjustments costume design, broaden enterprises in the fabric range of options on the favorable long-term development of enterprises of clothing.

Clothing structural design has strict requirements for integrated data error control, this is because the garment prototype requirements must be based on actual body measurements. China has 56 ethnic groups, according to 2014 statistics, about 1.368 billion people, a large population, shapes, size and general survey of China also needs to keep up with prototyping, resulting in China's apparel design database size serious the defects, which gives Chinese garment design brings a high degree of difficulty.

China has 31 provinces, 337 cities, 2858 counties. Each region of the natural environment and climate are different, so-called side soil support people, so everyone's body is also different, the size of the structural design for the clothing requirements are also different. It is difficult to summarize the data with a prototype of a regional body for all, for costume design also adds a problem.

In the calendar year China International Garment Fair, Chinese exhibitors have no independent clothing brands, most of all, and some well-known foreign brands or certain agents of foreign brands, especially in China clothing structure design, China not have their own brand culture. As we all know, China is the largest producer of the labor force, many products are marked with Chinese-made signs, but the quality is not true, the main reason is the lack of Chinese local brand culture. In the apparel industry, there is no absolute advantage in China clothing enterprises in brand awareness, market acceptance and the like. There are a lot of own brand at birth, but brand awareness is not open, not enough to have any effect, it is in the low-end clothing brand. Some even own brand gradually be eliminated. 


\section{Development Of Chinese Clothing Structure Design}

Clothing structure design and the use of the hand-painted fashion designer. Through hand-painted clothing out, really beautiful, but hand-painted clothing designer has extensive structure needs experience in fashion design and rich imagination of a good three-dimensional thinking, this is a big challenge for many designers, and hand-painted clothing structure design the time it takes too long. But the use of multimedia software technology to achieve costume design, not only saves design time, and out of the clothing structure design three-dimensional structure can be presented clothing effect. If it does not meet the effect of clothing there is a need to modify the requirements of clothing or clothing structural design issues and other small details can be modified directly, the result of changes made after the modification is completed by the effect of three-dimensional structure of the clothing presented after compliance.

Want an outstanding costume design structure, it must establish a sound body costume design database. The establishment and improvement of the database data may be first of many multimedia technologies to collect data of the human body, formation of the initial database, and then followed by a prototype data for data matching, unified database, and finally to the data in the database will be perfect, there is no re-entry field measure, then enter the database. With the complete Chinese costume design database greatly helped the development of clothing design. But this is only a small step, China wants to gain the upper reaches of clothing design industry, but also requires constant effort and innovation. The first task is to seize the garment industry high-end market, you can take the "first-class enterprises selling brand, second-rate companies to sell technology, third-rate companies to sell products" ways. Because the development of enterprises are market driven.

International clothing apparel industry is the development trend of the situation development indicators, China want to develop clothing structure design better, to go further, we must design clothing and international standards, to keep up with the development of international situation. But we can not blindly follow the trend, and the international trend of blindly maintaining exactly the same structure in the clothing design, so there is no Chinese clothing structure design features, such as Chinese clothing can only walk a distance, slowly it will be annexed eliminated . The one hand, China needs and international standards in the clothing design, drawing on the advantages of international clothing in structural design, improvement in the structural shortcomings of the domestic apparel design aspects, one must establish the local Chinese clothing brand design, this Chinese clothing road to go further, go better.

\section{REFERENCE:}

[1] Sun Ying, Gan Jingyuan. research into the status quo of China's apparel design and development [J]. Sichuan silk, 2005,03: 36-39.

[2] Li Liang. Chinese modern clothing design methods research [D]. Central Academy of Fine Arts, 2009.

[3] Wei Jing, Han Yingbin. status of costume design education, the status quo and reform [J]. Ningbo University (Educational Science Edition), 2001,02: 62-64.

[4] Liu Yiqian. Based on intelligent clothing structure graphic design application platform network research [D]. Donghua University, 2004. 